\title{
Postextractive implants in aesthetic areas: evaluation of perimplant bone remodeling over time
}

\author{
Michele Mario Figliuzzi, DDS, PhD \\ Amerigo Giudice, DDS, PhD \\ Maria Giulia Cristofaro, DDS, PhD \\ Delfina Pacifico, DDS \\ Pasquale Biamonte, DDS \\ Leonzio Fortunato, DDS, PhD
}

Department of Periodontics and Oral Sciences, University "Magna Graecia" Catanzaro, Italy

Corresponding author:

Michele Mario Figliuzzi

Department of Periodontics and Oral Sciences, University "Magna Graecia" Catanzaro

Via De Maria, 9

89900 Vibo Valentia, Italy

Phone: +390963 592568

E-mail: figliuzzi@unicz.it

\section{Summary}

Aim. The aim of this research was to assess periimplant bone remodeling of post-extractive implants over 2 years.

Material and methods. 30 patients meeting pre-established inclusion criteria were enrolled for the study. One implant for each patient was inserted in the post-extraction sockets according to a defined surgical protocol (atramautic extraction, curettage of extraction socket, implant insertion, grafting with collagenated cortico-cancellous porcine bone, and a trimmed collagen membrane to completely cover the socket, suture). A temporary adhesive bridge, with an adequate profile, was bonded to the adjacent teeth. X-ray evaluation with a standardized stent was carried out at different times. Measurements were obtained from the implant edge to the bone peak. The values obtained at time 0 and at 2 years were compared by t-student test.

Result. Our results showed that after one year $73 \%$ of patient had $0 \mathrm{~mm}$ of bone reabsorption, $20 \%$ of patient had $0 \mathrm{~mm} \leq \mathrm{x} \leq 0.5 \mathrm{~mm}, 7 \%$ of patient had $0.5 \mathrm{~mm} \leq \mathrm{x} \leq 2 \mathrm{~mm}$ of bone reabsorption. After two years $62 \%$ of patient had $0 \mathrm{~mm}$ of bone reabsorption, $24 \%$ had $0 \mathrm{~mm} \leq \mathrm{x} \leq 0.5 \mathrm{~mm}, 14 \%$ had $0.5 \mathrm{~mm} \leq \mathrm{x} \leq 2 \mathrm{~mm}$.

Conclusions. The results showed no significant differences in bone reabsorption in most patients over 2 years.
Key words: dental implants, post-extractive implants, immediate loading, bone remodeling.

\section{Introduction}

Dental implants can be placed in edentulous sites at different times after tooth extractions. Some Authors (1) have indicated that the immediate placement could offer advantages including time saving. An immediate implant is placed in an extraction socket as part of the same procedure. In the past, clinicians allowed a socket healing time of up to 12 months or longer before placing implants to restore an edentulous space (2), leading to compromised comfort, function, and aesthetics for the patient.

To overcome this limitations, an immediate approach was introduced (3) despite some potential disadvantages. The possible lack of keratinized mucosa for flap adaptation makes primary closure more difficult to achieve and the incongruity of size and shape between implants and extraction sockets presents challenges for primary implant stability. While initial implant stability is obtained by intimate contact with the newly formed bone in healed sites, residual bony defects always exist around implants in immediate implantation. Consequently, primary stability is only achieved by anchoring the implant in the apical bony region (3-4 $\mathrm{mm}$ ), where cancellous bone predominates.

Some studies with a mean follow-up time of 3 years evaluated marginal bony alterations (4-9). It is known that post-extractive implants do not prevent bone resorption (10). Such biological changes imply higher risk of marginal mucosal recession after immediate implant placement, with possible aesthetical damage especially when the facial socket wall and tissue biotype are thin (11). Bone remodeling can be associated with three dimensional implant position, presence/absence of platform switching, absence of facial bony wall, inter implant/tooth distance.

It has been stated that a certain width of peri-implant mucosa is required to enable a proper epithelial-connective tissue attachment. In case of inadequate dimension, crestal bone reabsorption will occur to ensure the appropriate biological width. Recent studies have shown that for all two-piece implants, the bone crest level changes seem related to the microgap position $(12,13)$.

Histological and radiographic studies by Herman et al. have proven that a crestal bone loss of about 2 $\mathrm{mm}$ occurs with the submerged, two-pieces ap- 
proach, dependent on the microgap, and minimal or no reabsorption occurs with non-submerged, onepiece implants (14). They demonstrated that a rough/smooth border on the surface of one-piece implants determines the crestal bone levels adjacent to such implants. Regarding platform switching CalvoGuirado et al. (15) evaluated the survival rates at 12 months of a platform switched implant placed in the anterior and premolar areas of the maxilla and immediately restored with single crowns. They concluded that the implants remained stable over the course of 12 months and had an overall survival rate of $96.7 \%$. Minimal crestal bone loss was recorded around the surviving implants.

Furthermore, based on the finding that the bone crest was more apically located at sites with $<3 \mathrm{~mm}$ interimplant distance than at sites where the implants were standing $>3 \mathrm{~mm}$ apart, Tarnow et al. (16) suggested that not only vertical bone loss but also lateral bone loss at implants could have an effect on the level of the bone crest between two implants.

The aim of this research is focusing on the perimplant bone remodeling of post-extractive implants over two years.

\section{Materials and methods}

\section{Trial design}

\section{Participants:}

Selected patients for the study meet the following inclusion criteria:

- good health conditions (no systemic diseases including diabetes, rheumatic diseases, neoplasia)

- non smokers or smokers less of 15 cigarettes a day

- presence of adequate cortical bone at vestibular and palatal plates (at least $2 \mathrm{~mm}$ )

- presence of adjacent teeth

- sufficient vertical amount of bone (at least $3 \mathrm{~mm}$ of residual bone evaluated thorough CT dental scan) to insert a stable post-extractive implant.

Exclusion criteria were:

- pregnancy and lactation

- assumption of drugs such as biphosfonates which could negatively influence bone healing

- active periodontitis.

All patients required teeth extractions due to root fractures, destructive caries, endodontic failures. Each patients signed an informative approval form before acceptance of treatment. The research was conducted with the approval of local ethical committee nr. 926 of October 2010 and in accordance with the Helsinki Declaration.

\section{Surgical procedures}

All patients received prophylactic antibiotic therapy ( $2 \mathrm{~g}$ of amoxicillin or $600 \mathrm{mg}$ clindamycin - if allergic to penicillin) 1 hour before the extraction procedure and postoperative antibiotic therapy $(1 \mathrm{~g}$ amoxicillin or $300 \mathrm{mg}$ clindamycin) for further 4 days. All patients rinsed for 1 minute with chlorhexidine mouthwash $0.2 \%$ prior to surgery (and twice a day for the following 3 weeks), and were treated under local anesthetic using lidocaine with adrenaline 1:50.000. All surgical procedures were undertaken by one surgeon. All the patients were treated with the same surgical technique (periotomes were used around each single selected tooth); moreover the extraction socket was thoroughly curetted and irrigated with sterile saline solution. To preserve vestibular bone plate, some teeth extractions were performed using piezoelectric tips (Piezosurgery, EX2, Mectron, Italy). Implants (Sweden Martina, Due Carrare, Padova, Italy) were inserted placing the shoulder edge $1 \mathrm{~mm}$ deeper the cortical margin of palatal plate (Figs. 1, 2). Subsequently, the residual gaps were filled and slightly condensed with collagenatedcortico-cancellous porcine bone (MP3, OsteobiolTecnoss, Coazze, Italy), and a trimmed collagen membrane (Evolution, Osteobiol-Tecnoss, Coazze, Italy) was used to completely cover the socket. The

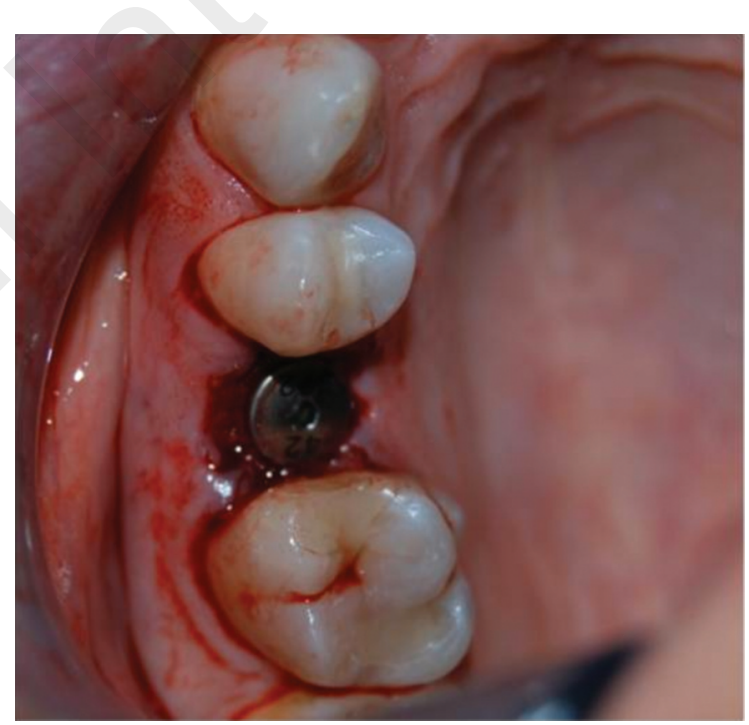

Figure 1. Implant placement after extraction.

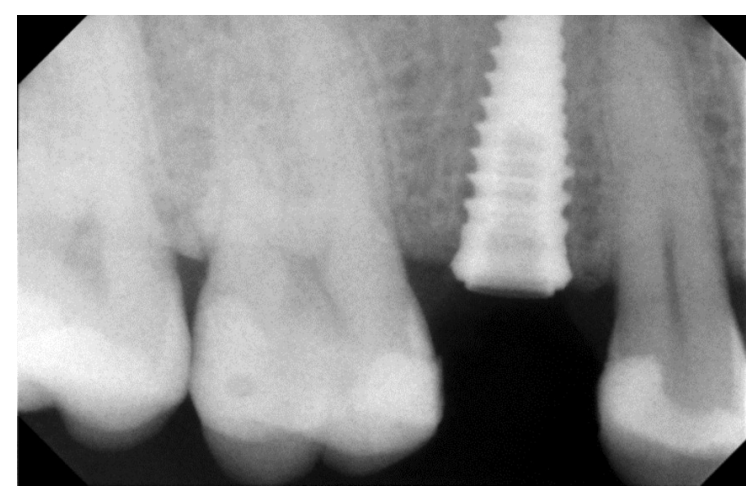

Figure 2. X-ray evaluation immediately after placement. 
soft tissues were only undermined and no releasing incisions were performed. Platelet-rich fibrin (PRF) membranes were prepared and used for better healing of soft tissues. The collagen membrane was left intentionally exposed to the oral cavity and stabilized by sutures.

All patients were instructed to continue with prophylactic antibiotic therapy; naproxen sodium $550 \mathrm{mg}$ tablets were prescribed as an anti-inflammatory to be taken 2 times a day for as long as required. The temporary prosthetic restoration was bonded to the adjacent teeth with a light-curing composite which was, subsequently, carefully polished. The profile of a temporary restoration was adapted to the edentulous space withflat profile at the buccal and proximal sites. This modified pontic profile would support the soft tissues thus allowing for a more natural shape of the gingivae and papillae; sutures were removed after 7 days.

Clinical follow up was performed until 24 months after surgery (Figs. 3-5). Three months after surgery final prosthetic restoration was delivered (Figs. 4, 5)

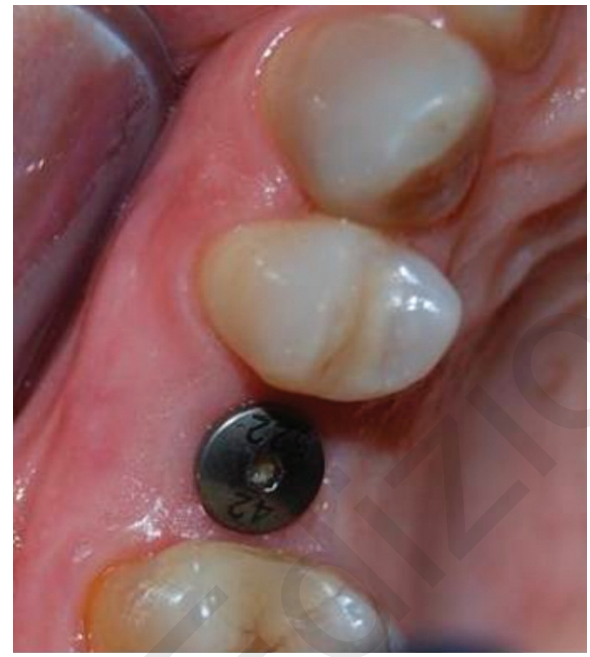

Figure 3. Clinical condition of site after 30 days.

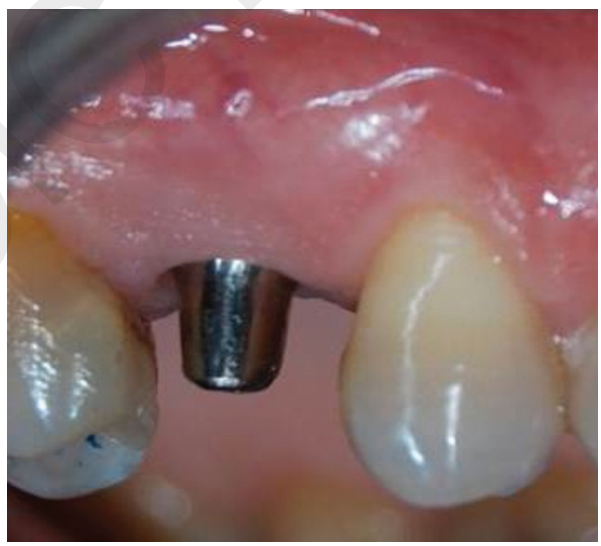

Figure 4. Clinical condition after 90 days and insertion of abutment.

\section{X-ray evaluation}

X-ray evaluation was carried out at different timing:

- time 0 at implant insertion

- 1 year after implant insertion

- 2 years after implant insertion.

Digital intra-oral periapical radiographs were taken (70 KVp, $7 \mathrm{~mA}$ ) using a parallel cone technique with a digital sensor (Schick Technologies, Long Island City, NY, USA). A paralleling device and individualised bite blocks, made of polyvinyl siloxane impression material (Flexitime, Heraeus/Kulzer, Hanu, Germany), were used for the standardization of the x-ray geometry. Bone loss was measured by using the radiographs taken at 0,12 and 24 months after implant insertion (Figs. 6, 7). The marginal bone height (MBL) was set

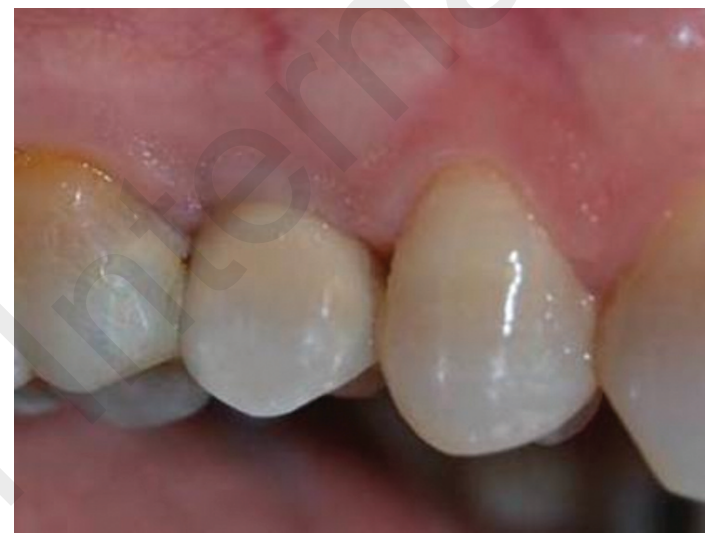

Figure 5. Clinical condition after 90 days.

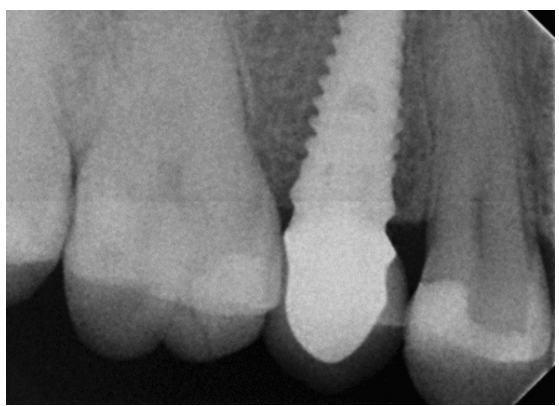

Figure 6. Bone remodeling after 1 year.

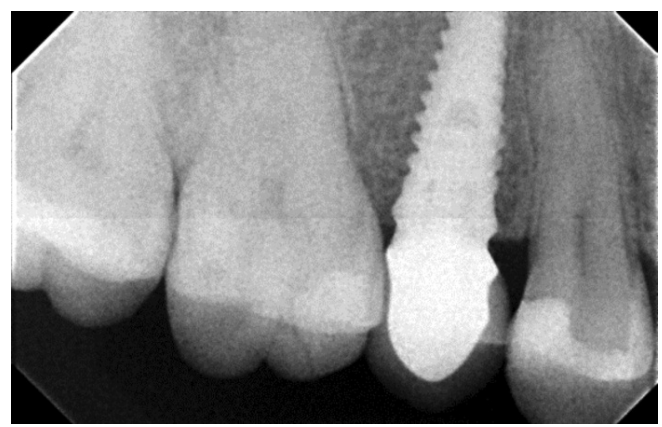

Figure 7. Bone remodeling after 2 years. 


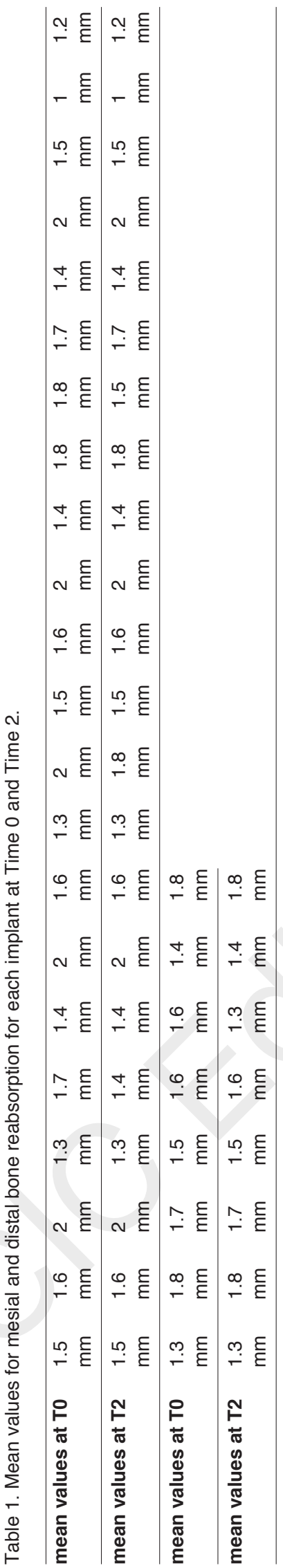

as the distance between the implant-abutment connection and the most apical point of the marginal bone level. Calibration was performed using the known thread-pitch distance of the implants (pitch $=$ $1.0 \mathrm{~mm}$ ). Previously known values, such as fixture diameter and length, were used for calibration when the threads were not clearly visible on the radiographs. Measurements were taken to the nearest $0.1 \mathrm{~mm}$ using computer software (UTHSCSA Image Tool, Version 3.00, University of Texas Health Science, San Antonio, TX). Bone changes were measured at the mesial and distal peri-implant sites, and their average values were used calculating distance between cortical edge and the fixture abutment junction. All measurements were taken by one examiner who was not involved in performing the surgical treatment. The values obtained at time 0 and at 2 years were compared by test t-student.

\section{Results}

Thirty-nine patients were initially screened for eligibility; however, 9 patients were excluded from the study because missing adjacent teeth and no integrity of the buccal bone plate immediately after extractions; 3 patients refused to be enrolled in a prospective study. Thirty patients (18 females and 12 males, mean age of $48 \pm 11.6$ years) were considered eligible and were consecutively enrolled and treated. No patients dropped out from the study and the data from all patients was evaluated in the statistical analysis. Eleven teeth (33\%) were removed using a piezosurgery tip to reduce the risk for buccal plate fracture and thus reducing the risk for further bone loss.

All treated sites allowed the placement of 3.75 or $4.25 \mathrm{~mm}$ implants. Implants were torqued at $30 \mathrm{~N}$ $\mathrm{cm}^{2}$. No complications were recorded during the healing period.

The mean values for the mesial and distal bone reabsorption for each implant at Time 0 and Time 2 (Tab. 1) were compared by test t-student and show that there were no significant differences in bone reabsorption after two years of implant insertion $(p=$ 0.5855) (Tab. 2).

All data were also selected and divided in three different categories:

I patients who did not have bone remodeling

II patients who had up to $0.5 \mathrm{~mm}$ of reabsorption

III patients who had a reabsorption from $0.5 \mathrm{~mm}$ to $2 \mathrm{~m}$.

The results for each groups are summarized in Figures $8,9$.

\section{Discussion}

Literature data showed that implants placed immediately in fresh extraction sockets represent a reliable procedure. Some authors indicated a low annual failure rate of $0.82 \%(95 \% \mathrm{Cl}: 0.48-1.39 \%)$ resulting in a survival rate of $98.4 \%$ at 2 -year (16). In systematic re- 
Table 2. T-student test from values at T0 and T2.

\begin{tabular}{llllll}
\hline & mean & Dev. Standard & $T$ & Degrees of freedom & P \\
\hline values at T0 & $1.6 \mathrm{~mm}$ & 0.2613 & $\mathbf{0 . 5 4 8 4}$ & $\mathbf{5 8}$ & $\mathbf{0 . 5 8 5 5}$ \\
values at T2 & $1.5633 \mathrm{~mm}$ & 0.2566 & & & \\
\hline
\end{tabular}

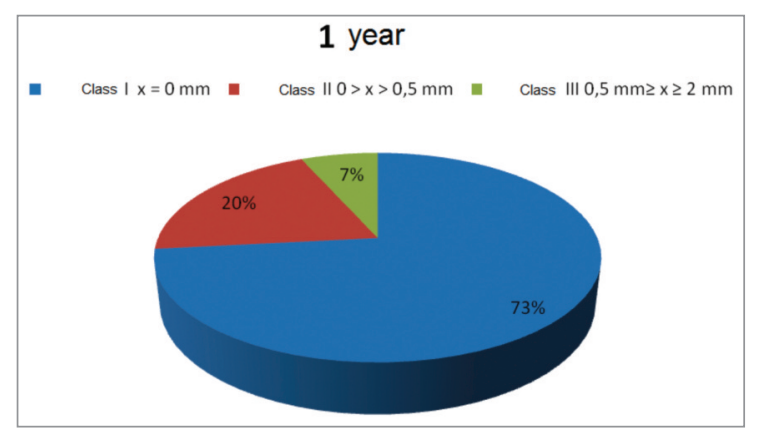

Figure 8. Results after 1 year.

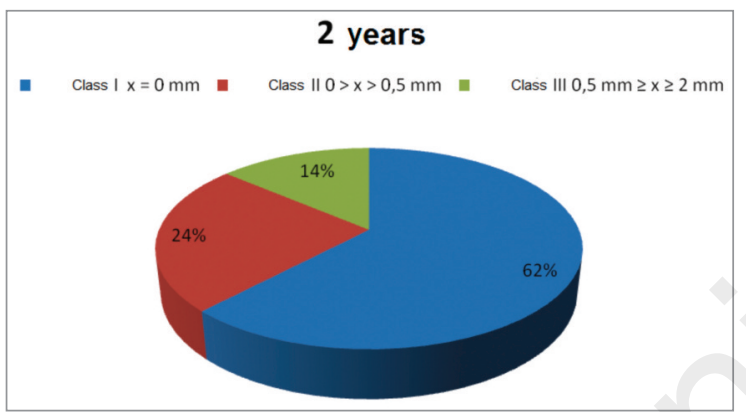

Figure 9. Results after 2 years.

views $(17,18)$, survival rates and complication occurrence of fixed dental prosthesis, formerly "fixed partial dentures" (FPDs) and single crowns supported by post-extractive implants were estimated. The 5-year survival rate of implants was $>95 \%$ and that of FPDs and SCs were approximately $95 \%$. Technical and biological complications were reasonably prevalent. In the review concerning peri-implant diseases (19), it was found that after 5-10 years of function, peri-implant mucositis occurred in approximately $80 \%$ of subjects and in $50 \%$ of implants. Peri-implantitis was found in $28-56 \%$ of the subjects and $12-43 \%$ of the implants. In this research no complications from a technical or a biological point of view were observed. In addition, our research highlighted bone changes similar to other studies (20). Generally, immediate implants in most studies experienced bone loss. The 1-year studies that the bone loss was less than $1 \mathrm{~mm}$ (range: gain $1 \mathrm{~mm}$ loss $0.98 \mathrm{~mm}$ ) in the first year, and longer-term studies demonstrated that after the first functioning year bone levels became stable (19). Our data indicated slightly higher changes but similar at 1 and 2-year follow up. Three studies (21-23) reported changes of marginal bone levels around immediately placed and immediately restored implants using the platform-switching method. In the study of Calvo-Guirado et al. (21), the mean bone loss after 1 year of function was $0.08 \mathrm{~mm}$ on the mesial surfaces and $0.09 \mathrm{~mm}$ on the distal sur- faces. The small bony changes were in accordance with those reported in the RCT by Canullo et al. (23), which showed that after about 2 years of loading, the platform-switching group experienced bone loss of $0.25 \mathrm{~mm}$ mesially and $0.36 \mathrm{~mm}$ distally; the bone loss was more significant in the platform-matching group, reaching $1.13 \mathrm{~mm}$ and $1.25 \mathrm{~mm}$ on mesial and distal surfaces, respectively. On the contrary, in the study by Crespi et al. (22), no significant differences in the bony changes between the two groups were found. The bone loss ranged $0.73-0.84 \mathrm{~mm}$ at the 1 - year followup and $0.68-0.80 \mathrm{~mm}$ at the end of the second year. Basing on our results, it should be hypothesized that platform switching could minimize bone remodeling after prosthetic loading. In addition, also bone grafting may have contributed to reduce bone remodeling. The placement of graft material has been indicated as an ideal procedure in order to maintain adequate bone levels, as demonstrated by lasella et al. (24). Comparable results have been found using similar techniques by Serino et al. (25) and Camargo et al. (26), who concluded that a slight bone loss at buccal and lingual aspects may occur despite preservation procedures.

This remodeling in response to inadequate blood supply becomes more critical in the buccal region for characteristics naturally inherent to this region's nature and anatomy (27). Current scientific literature reports that an alveolar ridge preservation technique has some benefits including less ridge reabsorption of the post-extractive sites (28), but emphasises that a complete preservation of the buccal area is nevertheless difficult (28). This fact could explain the bone remodeling up to $1 \mathrm{~mm}$ which we observed.

This research has some limitations. First of all the absence of a control group (only ridge preservation) makes our research partially elusive. Furthermore, the study includes in the same group mandibular and maxillary implants.

Our results need to be confirmed by other researches with a major numbers of mandibular and maxillary implants included in separated groups, and with a control group.

\section{References}

1. Hämmerle $\mathrm{CH}$, Chen ST, Wilson TG Jr. Consensus statements and recommended clinical procedures regarding the placement of implants in extraction sockets. Int J Oral Maxillofac Implants. 2004;19 Suppl:26-8.

2. Adell R, Lekholm U, Rockler B, Brånemark PIA 15-year study of osseointegrated implants in the treatment of the edentulous jaw.Int J Oral Surg. 1981 Dec;10(6):387-416.

3. Schulte W, Kleineikenscheidt H, Lindner K, Schareyka R. The Tübingen immediate implant in clinical studies. DtschZahnarztl Z. 1978 May;33(5):348-59. 
4. Becker W, Becker BE, Hujoel P.Retrospective case series analysis of the factors determining immediate implant placement. Compend Contin Educ Dent. 2000 Oct;21(10):805-8, 810-1.

5. Huys LW. Replacement therapy and the immediate post-extraction dental implant. Implant Dent. 2001;10(2):93-102.

6. Bianchi AE, Sanfilippo F. Single-tooth replacement by immediate implant and connective tissue graft: a 1-9-year clinical evaluation.Clin Oral Implants Res. 2004 Jun;15(3):26977.

7. Botticelli D, Renzi A, Lindhe J, Berglundh T. Implants in fresh extraction sockets: a prospective 5-year follow-up clinical study.Clin Oral Implants Res. 2008 Dec;19(12):1226-32.

8. Mijiritsky E, Mardinger O, Mazor Z, Chaushu G. Immediate provisionalization of single-tooth implants in fresh-extraction sites at the maxillary esthetic zone: up to 6 years of followup.Implant Dent. 2009 Aug;18(4):326-33.

9. Prosper L, Crespi R, Valenti E, Capparé P, Gherlone E. Fiveyear follow-up of wide-diameter implants placed in fresh molar extraction sockets in the mandible: immediate versus delayed loading.Int J Oral Maxillofac Implants. 2010 MayJun;25(3):607-12

10. Wang RE, Lang NP. Ridge preservation after tooth extraction. Clin oral Implant Res. 2012 Oct;23 Suppl 6:147-56.

11. De Rouck T, Collys K, Cosyn J. Single-tooth replacement in the anterior maxilla by means of immediate implantation and provisionalization: a review. Int J Oral Maxillofac Implants. 2008 Sep-Oct;23(5):897-904.

12. Wend D, Nagata MJ, Bosco AF, de Melo LG. Influence of microgap location and configuration on radiographic bone loss around submerged implants: an experimental study in dogs. Int J Oral Maxillofac Implants. 2011 Sep-Oct; 26(5): 941-6

13. Wend D, Nagata MJ, Leite CM, de Melo LG, Bosco AF. In fluence of microgap location and configuration on radiographic bone loss in nonsubmerged implants: an experimental study in dogs. Int J Oral Prosthodont. 2011 Sep-Oct; 24(5): 445-52.

14. Hermann F, Lerner H, Palti A. Factors influencing the preservation of the periimplant marginal bone. Implant Dent. 2007 Jun;16(2):165-75.

15. Calvo-Guirado JL, Gómez-Moreno G, Aguilar-Salvatierra A, Guardia J, Delgado-Ruiz RA, Romanos GE. Marginal bone loss evaluation around immediate non-occlusalmicrothreaded implants placed in fresh extraction sockets in the maxilla: a 3-year study. Clin Oral Implants Res. 2014 Jan 15 doi: 10.111.

16. Tarnow DP, Cho SC, Wallace SS. The effect of inter-implant distance on the height of inter-implant bone crest. J Periodontol. 2000 Apr;71(4):546-9.

17. Pjetursson $B E$, Tan $K$, Lang NP, Brägger U, Egger M, Zwahlen M. A systematic review of the survival and complication rates of fixed partial dentures (FPDs) after an ob- servation period of at least 5 years. Clin Oral Implants Res. 2004 Dec;15(6):667-76.

18. Jung RE, Thoma DS, HammerleCH.Assessment of the potential of growth factors for localized alveolar ridge augmentation: a systematic review.J ClinPeriodontol. 2008 Sep;35(8 Suppl):255-81.

19. Zitzmann NU, Berglundh T Definition and prevalence of periimplant diseases. J Clin Periodontol. 2008 Sep;35(8 Suppl):286-91

20. Fransson C, Lekholm U, Jemt T, Berglundh T. Prevalence of subjects withprogressive bone loss at implants. Clin Oral Implants Res. 2005 Aug;16(4):440-6.

21. Calvo-Guirado JL, Ortiz-Ruiz AJ, López-Marí L, Delgado-Ruiz R, Maté-Sánchez J, Bravo Gonzalez LA.Immediate maxillary restoration of single-tooth implants using platform switching for crestal bone preservation: a 12-month study. Int J Oral Maxillofac Implants. 2009 Mar-Apr;24(2):275-81.

22. Crespi R, Capparè $P$, Gherlone E. Radiographic evaluation of marginal bone levels around platform-switched and nonplatform-switched implants used in an immediate loading protocol. Int J Oral Maxillofac Implants. 2009 Sep-Oct;24(5):9206 .

23. Canullo L, Goglia G, lurlaro G, lannello G. Short-term bone level observations associated with platform switching in immediately placed and restored single maxillary implants: a preliminary report. Int J Prosthodont. 2009 May-Jun;22(3):27782.

24. Iasella JM1, Greenwell H, Miller RL, Hill M, Drisko C, Bohra AA, Scheetz JP. Ridge preservation with freeze-dried bone allograft and a collagen membrane compared to extraction alone for implant site development: a clinical and histologic study in humans. J Periodontol. 2003 Jul;74(7):990-9.

25. Serino G1, Biancu S, lezzi G, Piattelli A. Ridge preservation following tooth extraction using a polylactide and polyglycolide sponge as space filler: a clinical and histological study in humans.Clin Oral Implants Res. 2003 Oct;14(5):651-8.

26. Camargo PM, Lekovic V, Weinlaender M, Nedic M, Vasilic $\mathrm{N}$, Wolinsky LE, Kenney EB. A controlled re-entry study on the effectiveness of bovine porous bone mineral used in combination with a collagen membrane of porcine origin in the treatment of intrabony defects in humans. J Clin Periodontol. 2000 Dec;27(12):889-96.

27. Novaes AB Jr, Suaid F, Queiroz AC, Muglia VA, Souza SL, Palioto DB, Taba M Jr, Grisi MF. Buccal bone plate remodeling after immediate implant placement with and without synthetic bone grafting and flapless surgery: radiographic study in dogs. J Oral Implantol. 2012 Dec;38(6):687-98.

28. Barone A, Ricci M, Covani U, Nannmark U, Azarmehr I, Calvo-Guirado JL. Maxillary sinus augmentation using prehydratedcorticocancellous porcine bone: hystomorphometric evaluation after 6 months. Clin Implant Dent Relat Res. 2012 Jun;14(3):373-9. 